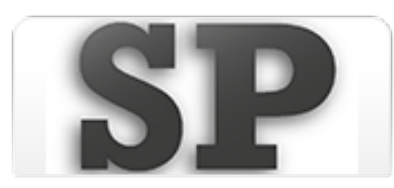

Sociedades Precapitalistas, vol. 8, nº 1, e029, diciembre 2018. ISSN 2250-5121 Universidad Nacional de La Plata.

Facultad de Humanidades y Ciencias de la Educación.

Centro de Estudios de Sociedades Precapitalistas (CESP)

\title{
Una aplicación de la morfometría geométrica al estudio de las variaciones morfológicas de los retratos de la tumba de Neferhotep -TT49-, Dinastía XVIII, Reino Nuevo, Egipto
}

\author{
Judith Charlin \\ Instituto Multidisciplinario de Historia y Ciencias Humanas, Consejo Nacional de Investigaciones \\ Científicas y Técnicas; Universidad de Buenos Aires, Argentina \\ judith.charlin@gmail.com

\section{Liliana Manzi} \\ Instituto Multidisciplinario de Historia y Ciencias Humanas, Consejo Nacional de Investigaciones \\ Científicas y Técnicas; Universidad de Buenos Aires, Argentina \\ Im_manzi@yahoo.com.ar
}

Cita sugerida: Charlin, J. y Manzi, L. (2018). Una aplicación de la morfometría geométrica al estudio de las variaciones morfológicas de los retratos de la tumba de Neferhotep -TT49-, Dinastía XVIII, Reino Nuevo, Egipto. Sociedades Precapitalistas, 8(1), e029. https://doi.org/10.24215/22505121e029

Recibido: 27 febrero 2018 - Aceptado: 05 octubre 2018 - Publicado: 07 diciembre 2018 
Una aplicación de la morfometría geométrica al estudio de las variaciones morfológicas de los retratos de la tumba de Neferhotep -TT49-, Dinastía XVIII, Reino Nuevo, Egipto

A geometric morphometrics application to study potrait shape variations from Neferhotep's tomb -TT49-, XVIII Dinasty, New Kingdom, Egypt

Judith Charlin

Instituto Multidisciplinario de Historia y Ciencias

Humanas, Consejo Nacional de Investigaciones Cientificas y

Técnicas; Universidad de Buenos Aires, Argentina

judith.charlin@gmail.com

Liliana Manzi

Instituto Multidisciplinario de Historia y Ciencias

Humanas, Consejo Nacional de Investigaciones Cientificas y

Técnicas; Universidad de Buenos Aires, Argentina

lm_manzi@yahoo.com.ar

\section{Resumen:}

Nuestro interés es evaluar la existencia de diferencias morfológicas en el modo de representar los perfiles de hombres y mujeres y entre grupos de individuos con diferente estatus social. Los resultados alcanzados indican la existencia de diferencias significativas estadísticamente en ambos casos, lo cual sugiere la existencia de cánones o normas en los modos de representación de los perfiles humanos según los grupos de individuos diferenciados. Así, consideramos que las herramientas metodológicas que ofrece la morfometría geométrica constituyen una novedosa y fructífera estrategia de aproximación al estudio de la variabilidad en la producción de imágenes en el Reino Nuevo (ca. 1550-1200 a.C.) pasibles de ser aplicadas a otros contextos de interés.

En el presente trabajo nos proponemos evaluar la existencia de variaciones morfológicas en una muestra de rostros representados en la Tumba de Neferhotep -TT49-, datada a finales de la dinastía XVIII (Reino Nuevo, Egipto), utilizando para su análisis las técnicas estadísticas multivariadas de la morfometría geométrica. El objetivo consiste en reconocer cuantitativamente variaciones en la forma de los retratos mediante la aplicación de métodos basados en landmarks sobre imágenes digitales -fotografías y calcosde perfiles humanos presentes en el registro epigráfico de esta tumba tebana.

Palabras clave: Representaciones parietales, Variabilidad morfológica, Morfometría geométrica, Perfiles, Tumba de Neferhotep, Reino Nuevo, Egipto.

\section{Abstract:}

The purpose of this work is to study morphological variations in a sample of portraits from Neferhotep's tomb -TT49-, dated to the end of the XVIII dynasty (New Kingdom, Egypt), applying geometric morphometric techniques. The main aim is analyze quantitatively the portrait shape variations by means of landmark-based methods, using photographs and digitized traced designs from the portraits of the epigraphic record of the Theban tomb.

Our interest is to assess the existence of shape variations between female and male portraits and among individuals of different social rank. The analyses show there are significant morphological differences in both cases, suggesting the existence of canons or rules in the representation of human portraits according to the groups of individuals identified here. Therefore geometric morphometric methods are a useful and innovative statistical tool to study shape variations in the funerary record during the New Kingdom (ca. 1550-1200 B.C.) that might be also applied to other study contexts.

KEYWORDS: Wall representations, Shape variability, Geometric morphometrics, Profile portraits, Neferhotep's tomb, New Kingdom, Egypt. 


\section{LA TUMBA COMO OFRENDA Y LUGAR DE CULTO FUNERARIO}

En la cosmovisión del antiguo Egipto la muerte fue concebida como una contra-imagen de la vida (Assmann, 2005). A través de su negación, el universo del más allá se llenó de contenidos, cuya sensualidad y expresividad eran una exaltación de la vitalidad y una negación de la finitud de la condición humana.

Las creencias funerarias resultaron en la creación de fórmulas capaces de conjurar la aniquilación y en la búsqueda de recursos materiales e inmateriales aptos para alcanzar una dimensión eterna, a través de una articulación entre fuerzas que daban sentido infinito al individuo (Pereyra, 2011a).

La concesión de una tumba, la decoración de sus paredes interiores y el equipamiento funerario fueron precondiciones necesarias para superar la crisis de la muerte y "no morir". Su otorgamiento constituyó un don otorgado por el faraón a sus súbditos con perspectiva funeraria, como garante de la superviviencia de su ka. La tumba puede ser entendida como una ofrenda que el rey y el dios conceden (Parra Ortiz, 2011: 137), a la vez que contiene las entregas materiales y diversas clases de ofrendas representadas en expresiones parietales.

La construcción de los monumentos, así como las representaciones que los decoran, fueron parte de estrategias de creación planificadas y ejecutadas por el estado, quien además contribuía a su sostenimiento material, incluso una vez que la tumba era otorgada a un miembro de la elite. Ante esta clase de supervisión, se espera que las expresiones iconográficas evidencien escasas variaciones a lo largo del período faraónico.

La tumba de Neferhotep (TT49), emplazada en la colina de el-Khokha (Figura 1), es un monumento funerario concedido a un miembro de la elite tebana durante el reinado de Ay (1327-1323 a.C.), según se observa en la cartela real preservada en el vestíbulo. Su propietario pudo ser individualizado en el registro epigráfico contenido en el interior de la estructura, reconociéndose su nombre, fisonomía y desempeño como funcionario del templo de Amón en Karnak, además del nombre y títulos de su esposa, padres, abuelo y bisabuelo (Davies, 1933; Pereyra et al., 2006).

Los retratos sintetizan en imagen ciertos rasgos que caracterizan a los individuos y grupos de personas, los cuales fueron representados de cuerpo entero y realizando diversas acciones. Así, la producción de las representaciones se enmarca en contextos históricos y culturales específicos que tuvieron la facultad de trascenderlos (Manzi, 2016) y conforman el material de análisis para comprender la lógica subyacente a las prácticas funerarias del Reino Nuevo. Sin embargo, en este trabajo solamente son analizados los rostros, ya que por cuestiones metodológicas (ver infra) es necesario mantener la homología entre las imágenes a ser comparadas.

Las representaciones del propio Neferhotep, dueño de la tumba, y del resto de los agentes sociales, incluso de aquellos que desconocemos si tuvieron existencia real, fueron pensadas y realizadas cuando éste se encontraba aún en vida. En consecuencia, su participación en las escenas de referencia pretende dar cuenta de una situación verídica, en donde se plasmaron sus intervenciones en la celebración de festividades, en el momento en que fue recompensado por el faraón y en la entrega del bouquet de Amón a su esposa, mientras que otras escenas son una recreación imaginaria, como es el caso del recibimiento de sus padres en el más allá y de la celebración de los ritos funerarios que ocurrirán a su muerte (ver láminas y análisis en Davies, 1933; Fantechi y Zingarelli, 2003; Pereyra, 2011b, 2012, entre otros). 
FIGURA 1.

Emplazamiento de TT49 en la colina de el-Khokha, Tebas occidental, Egipto.

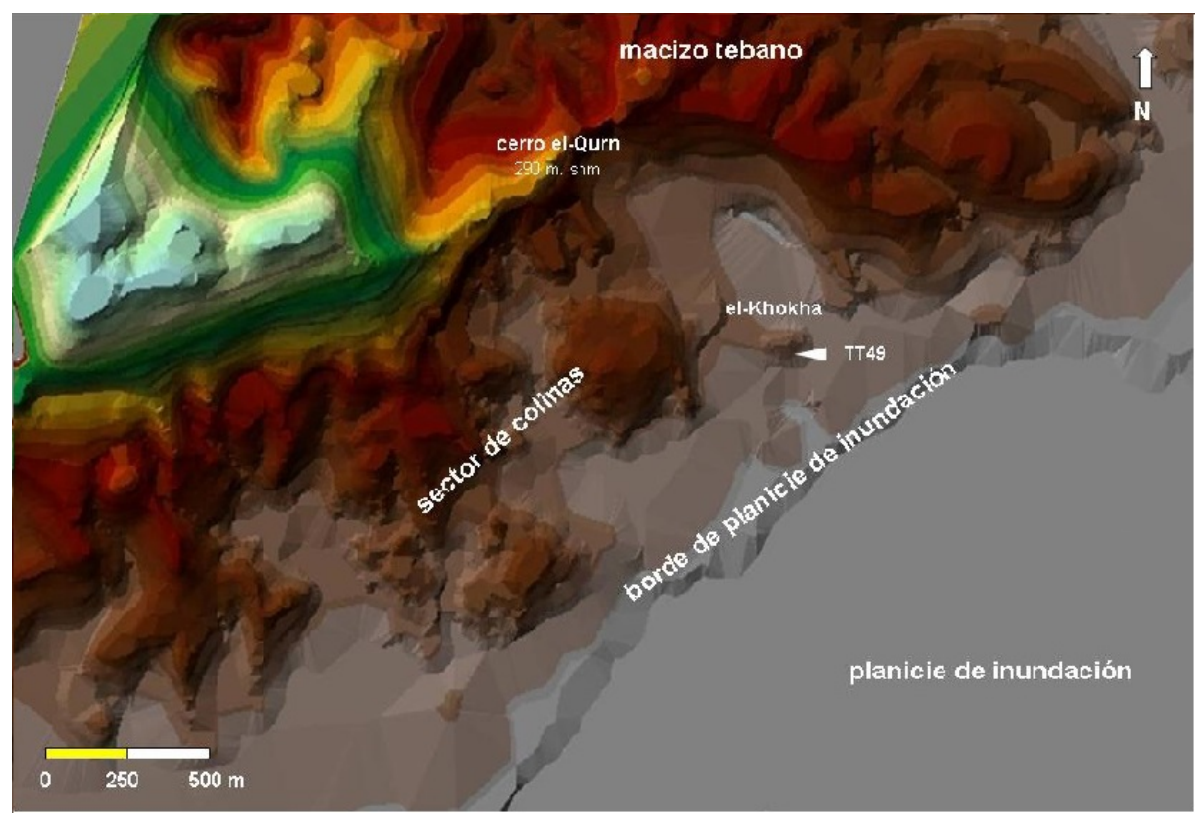

En consecuencia, la ubicación de cada monumento en el ámbito de la necrópolis (Manzi, 2012), el plano arquitectónico de las tumbas (Kampp, 1996; Porter y Moss, 1985) y la decoración iconográfica e inscripciones contenidas (Pereyra et al., 2006) deben interpretarse atendiendo a la información autobiográfica de su beneficiario, a su contexto histórico y a su proyección en el más allá (Assmann, 2004; Pereyra et al., 2006), previendo encontrar cierta homogeneidad dentro de la elite tebana, la cual puede corresponderse con el rango y las funciones del propietario en combinación con programas decorativos supervisados por el estado.

\section{OBJetivos Y ANTECEDENTES}

En el presente trabajo nos proponemos analizar desde una perspectiva cuantitativa la existencia de variaciones en la forma de las representaciones (con independencia del tamaño) de los retratos de los diferentes individuos presentes en la decoración mural de la Tumba de Neferhotep. Para alcanzar este objetivo se utilizarán técnicas estadísticas multivariadas conocidas como morfometría geométrica (Bookstein, 1991; Rolhf y Bookstein, 1990, entre otros. Ver infra)

El registro epigráfico de TT49 presenta diferentes grados de visibilidad y conservación debido a los complejos procesos ocupacionales y post-ocupacionales que tuvieron lugar en su interior, y que llevaron a que buena parte de la decoración se encuentre severamente dañada (Manzi, 2009-2010; Pereyra et al., 2006). Por este motivo, el estudio que aquí se presenta toma como muestra de análisis solamente los perfiles de los rostros de los individuos, ya que por problemas de preservación (y otros requisitos del método, ver infra) resulta imposible incluir figuras enteras u otros rasgos faciales, como los ojos, a pesar de su gran importancia en los modos de representación del antiguo Egipto. Un requisito indispensable para el análisis es que los rasgos analizados tengan una representación reiterada, de modo que sea posibilite medir su homogeneidad / variabilidad.

El análisis morfométrico que aquí presentamos busca evaluar semejanzas y diferencias morfológicas en los rostros de los diferentes individuos representados en dos casos en particular: 1. Entre retratos femeninos y 
masculinos, con el fin de evaluar la existencia de cánones de representación dependientes del sexo, 2. Entre retratos de diferentes personajes agrupados de acuerdo con su estatus o desempeño en la sociedad tebana.

Las primeras aplicaciones de la morfometría geométrica a las representaciones de la TT49 estuvieron orientadas a evaluar la variabilidad en el propio retrato de Neferhotep (Charlin y Manzi, 2017; Pereyra, Charlin y Manzi, 2016). Con dicho objetivo se compararon los retratos localizados en las paredes norte y sur de la tumba, contemplando la posibilidad de que existieran variaciones debido a su ejecución por parte de distintas cuadrillas de artesanos, como lo proponen otros estudios (Carpiceci, 2009; Choisy, 2007; Hermoso Cuesta, 2008). Sin embargo, si bien se registraron variaciones entre los retratos, las mismas no mostraban un patrón diferencial en correspondencia con su localización en las paredes norte y sur, por lo cual no fue posible refutar la hipótesis nula de igualdad en la forma promedio de los retratos representados en ambos muros. Si bien la expectativa inicial era encontrar variaciones morfológicas para sostener la participación de diferentes cuadrillas de artesanos u operarios, ésta evidencia no fue aportada por las comparaciones realizadas a partir del retrato del dueño de la tumba (Charlin y Manzi, 2017; Pereyra et al., 2016). Sin embargo, no es posible descartar plenamente la participación de diferentes grupos operando en la ejecución de las pinturas parietales de la TT49 si consideramos la existencia de procesos de equifinalidad y de un programa decorativo altamente pautado (ver Conclusiones).

\section{METOdología: los MÉTOdos y TÉCNICAS dE LA MORFOMETRÍA GEOMÉTRICA}

La morfometría geométrica (MG) comprende el estudio cuantitativo de la forma mediante las coordenadas cartesianas $(x, y)$ de un conjunto de puntos discretos denominados landmarks (Bookstein, 1991) utilizados para capturar la forma del objeto de estudio (en 2 o 3 dimensiones). Estas técnicas, cuyo origen radica en la biología, han comenzado a ser aplicadas frecuentemente en la arqueología, principalmente al estudio de la forma de los artefactos líticos (Buchanan et al., 2011; 2014; Cardillo, 2005; Charlin y GonzálezJosé, 2012; Charlin, Cardillo y Borrazzo, 2014; Shott y Trail, 2010, entre otros) y de los huesos humanos (Ackerman, 2002; Bastir, Rosas y Sheets, 2005; González-José, Bortolini, Rodriges Dos Santos y Bonnato, 2008; Mitteroecker y Bookstein, 2008, entre otros). Recientemente, se ha explorado su aplicación al estudio de las representaciones gráficas rupestres (pinturas y grabados), arrojando resultados prometedores (Charlin y Hernández Llosas, 2016) que nos estimulan a emprender el estudio de la decoración funeraria de la TT49.

En MG, la forma es entendida como la información geométrica que permanece una vez eliminados los efectos de traslación, rotación y escala (Kendall, 1977; 1989). Así, la forma se convierte en una variable independiente del tamaño, siendo posible estudiar sus interrelaciones (Bookstein, 1991; Zelditch, Swiderski, Sheets y Fink, 2004). Las técnicas utilizadas se sustentan en los métodos basados en landmarks (Bookstein, 1991; Marcus, Bello y Garcia-Valdecasas, 1993; Rohlf y Bookstein, 1990; Slice, 2005). Los landmarks (LMs) son puntos discretos que describen la forma de un objeto a través de su ubicación en el espacio y deben ser identificados con precisión y de forma reiterada en diferentes objetos de la misma clase, es decir, deben ser puntos homólogos (Zelditch et al., 2004). La homología puede responder a factores biológicos, ya sean filogenéticos u ontogenéticos, como así también a principios geométricos, es decir respetando la misma posición topológica relativa (Bookstein, 1991; Zelditch et al., 2004). En el caso aquí presentado, donde el objeto de estudio es el perfil humano, se han utilizado cinco landmarks para dar cuenta de los rasgos anatómicos faciales que son homólogos entre los distintos personajes considerados.

Los semilandmarks (SMLs) son un tipo particular de puntos morfométricos que se usan para describir curvas o superficies que, si bien son estructuras homólogas entre los individuos, no presentan puntos discretos identificables (Bookstein, 1991; 1996/7). Los SMLs pueden ser comprendidos como puntos arbitrarios dispuestos entre dos landmarks (Bookstein, 1996/7). En nuestro caso de estudio, hemos utilizado 13 semilandmarks para capturar la forma en sectores del rostro que no presentan atributos distinguibles como 
la frente, que muestra variaciones en su extensión y curvatura relativa, o los labios, que en muchos casos no se encuentran diferenciados (ver Figura 2 para la ubicación de LMs y SMLs en los retratos).

A través de los métodos basados en landmarks es posible estudiar los cambios morfológicos entre individuos (retratos) a partir de las variaciones en la posición relativa de los puntos morfométricos (luego de su estandarización), es decir evaluando sus desplazamientos mediante la superposición de las imágenes (Bookstein, 1991). Este procedimiento es conocido como el método de Procrustes o análisis generalizado de Procrustes, el cual implica la superposición de los objetos a ser estudiados, eliminando las variaciones producto de la rotación, traslación y tamaño (Rohlf, 1990; Rohlf y Slice, 1990). Los parámetros de forma son estimados mediante el análisis generalizado de Procrustes y sus variaciones pueden ser expresadas en forma gráfica, lo cual constituye una gran ventaja para todo tipo de estudios, pero en particular para el caso de las representaciones plásticas.

De este modo, la variable forma queda representada por dos coordenadas por cada punto morfométrico (LMs y SMLs), los cuales varían en número de acuerdo con el objeto de estudio y la problemática de interés.

El estudio de las variaciones morfológicas mediante estos métodos requiere de imágenes digitales del objeto de estudio, ya que la estimación de la forma de cada objeto se obtiene mediante la ubicación de LMs y SMLs en las imágenes y su posterior estandarización y superposición (a través del método de Procrustes). Así, para el estudio morfológico de los retratos de la TT49 hemos utilizado un total de 18 puntos morfométricos para capturar la forma del perfil (5 landmarks y 13 semilandmarks).

Existe una gran variedad de programas computacionales para trabajar con las imágenes y aplicar las técnicas de MG que son de acceso libre y se encuentran disponibles en http://life.bio.sunysb.edu/morph/ y http: //cran.r-project.org/. En particular hemos utilizado la serie Thin plate spline (tps) para conformar la base de datos digital y compilar los archivos de imagen para su estudio (tps Utility ver. 1.40, Rohlf, 2008), para realizar la digitalización de los puntos morfométricos (tps Digitizing 2 ver. 2.17, Rohlf, 2013a) y para estimar las coordenadas de forma mediante el análisis generalizado de Procrustes (tpsRewl ver. 1.53, Rohlf, 2013b). Finalmente, las coordenadas de forma obtenidas mediante estos procedimientos fueron exportadas al MorphoJ (ver. 1.06b, Klingenberg, 2011) y PAST (ver. 3.15, Hammer, Harper y Ryan, 2001) para realizar los análisis estadísticos multivariados de interés, como el análisis de componentes principales y el análisis discriminante (de dos y más grupos) persiguiendo los objetivos anteriormente señalados. 
FIGURA 2.

Localización de landmarks (puntos grises) y semilandmarks (puntos negros) en los retratos de TT49.

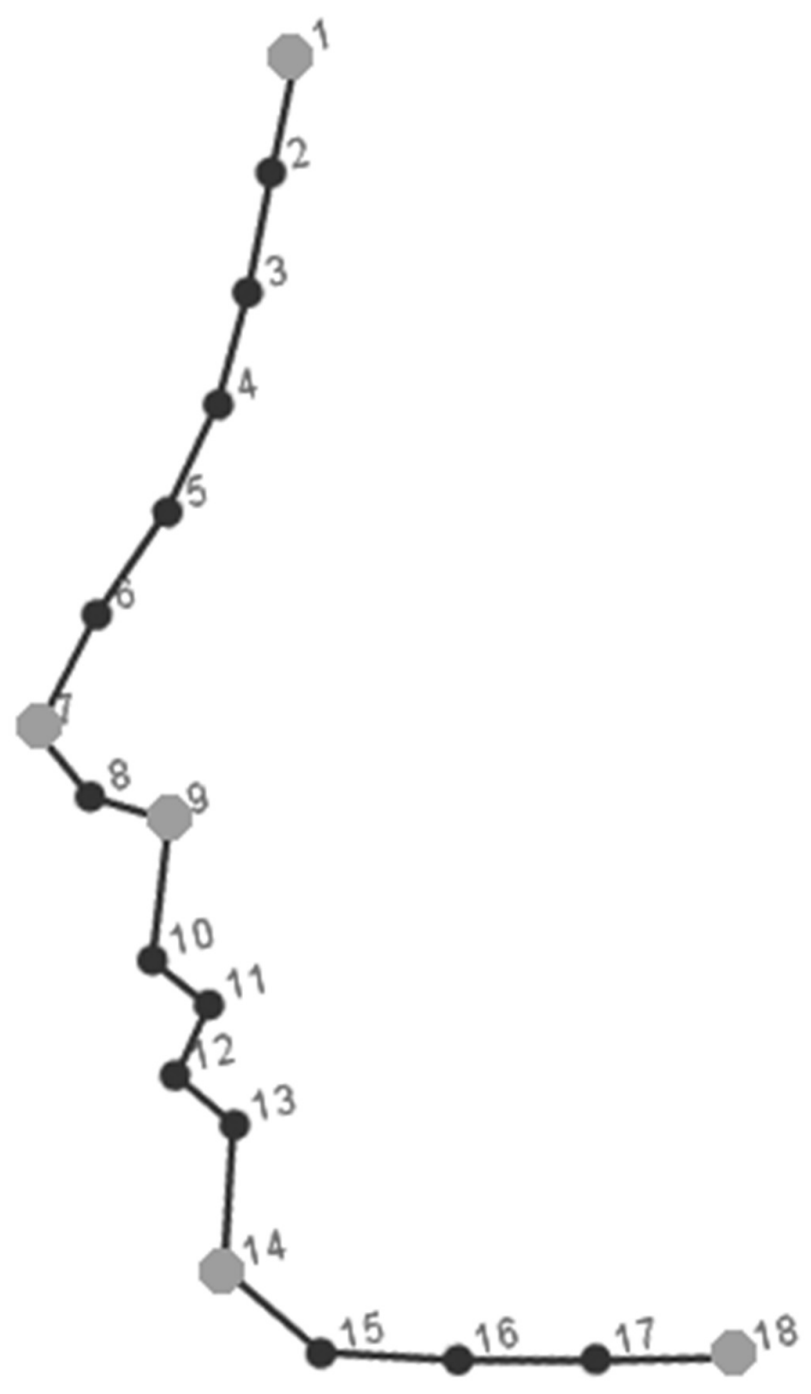

\subsection{Análisis de componentes principales}

El análisis de componentes principales $(\mathrm{ACP})$ es un método de ordenación que describe las variaciones de los individuos en un conjunto de datos, mostrando las principales tendencias de cambio (Manly, 1994). En sus aplicaciones en MG, utilizando las coordenadas de forma como variable morfológica, también es denominado análisis de deformaciones relativas o "relative warp analysis" (Bookstein, 1991; Rohlf, 1993). El ACP reduce las variaciones del conjunto de datos a un número de componentes que dan cuenta de distintos porcentajes de varianza en orden decreciente. En consecuencia, los primeros componentes son los que muestran las variaciones más frecuentes en la muestra.

Cada componente (también denominado autovector o eigenvector) es una combinación lineal de las variables que covarían y son independientes entre sí (ortogonales), lo cual significa que cada componente mide diferentes dimensiones en los datos (Manly, 1994). Así, el componente 1 es la dirección en la cual la muestra tiene la mayor varianza (Zelditch et al., 2004). La posición de los individuos (casos) en el plano está dada por un puntaje por componente (component score) que es el resultado de la combinación 
lineal de las variables ponderadas por sus respectivos coeficientes. Así, el puntaje para un individuo por componente (component score) es esencialmente un promedio ponderado de las variables que resume dicho componente. Estos puntajes pueden ser utilizados posteriormente como variables independientes en otros análisis estadísticos, en nuestro caso como variables de forma.

En síntesis, el ACP permite explorar los principales ejes de variación y reducir la dimensionalidad de los datos. Este análisis aplicado sobre las coordenadas de forma de Procrustes, permite describir la diversidad de formas en una muestra, identificando las principales variaciones morfológicas (Zelditch et al., 2004). Las variaciones de los individuos son evaluadas a partir de la forma promedio (o consenso), que representa la tendencia central de la muestra (Bookstein, 1996). Como las coordenadas de forma están medidas en la misma unidad, en MG siempre se utiliza la matriz de covarianza para efectuar el ACP (Mitteroecker y Gunz, 2009).

\subsection{Análisis discriminante}

El análisis discriminante (AD), en sus variantes para dos o más grupos (en este último caso generalmente denominado análisis de variantes canónicas, Webster y Sheets, 2010) centra su descripción en las diferencias entre grupos, en lugar de las variaciones entre individuos (Zelditch et al., 2004). Por este motivo requiere que los individuos estén clasificados a priori en grupos mutuamente excluyentes. Su objetivo es determinar si los grupos previamente establecidos (en base a variables extrínsecas al análisis) difieren entre sí y en qué forma (Strauss, 2010). El AD busca los ejes que optimizan las diferencias entre grupos en relación con la varianza interna al grupo. Del mismo modo que el ACP, el AD construye un nuevo sistema de coordenadas que son combinaciones lineales de las variables originales y mutuamente independientes, pero en este caso las variables maximizan la separación entre grupos (Strauss, 2010; Webster y Sheets, 2010). Así, la función discriminante es la que provee la mejor discriminación entre grupos (Zelditch et al., 2004). La efectividad del AD en asignar individuos a grupos previamente determinados (en base a otras variables) puede ser evaluada a partir de una validación cruzada, frecuentemente utilizando un procedimiento "leave one out" como el Jackknife (Hammer, 1999-2017; Webster y Sheets, 2010). Mediante la función discriminante, cada individuo es asignado a un grupo según la distancia mínima (distancia de Mahalanobis) a la media de grupo. En general, el porcentaje de asignación correcta de los individuos a los grupos definidos a priori es sobrestimado mediante este procedimiento ya que los mismos individuos a ser clasificados participan en el cálculo de la media de grupo. Por el contrario, la validación cruzada mediante Jackknife resulta más confiable dado que omite consecutivamente los individuos a ser clasificados del cálculo de la media. Así, los considera como "desconocidos", recalcula la media de grupo en cada caso y luego asigna cada individuo a un grupo según la distancia mínima (Hammer, 1999-2017; Webster y Sheets, 2010). Por este motivo, la tasa de clasificación correcta mediante la función discriminante es siempre más alta con respecto a la validación cruzada, pero este último método es el que sustenta una clasificación más confiable (Hammer, 1999-2017; Thulman, 2012; Webster y Sheets, 2010).

Por otro lado, utilizando la distancia de Mahalanobis es posible realizar un test de hipótesis y poner a prueba la hipótesis nula de igualdad entre las medias de grupo en base a la matriz de covarianza entre grupos.

En el presente trabajo, el AD fue implementado con el objetivo de identificar diferencias morfológicas en las representaciones de los retratos de la TT49 según el sexo y de acuerdo con el rango social o desempeño de los personajes. Por consiguiente, el sexo y el rango social fueron las variables de grupo definidas a priori contra las cuales se evaluaron las variaciones morfológicas. 


\subsection{Composición de la muestra}

La muestra total de retratos analizada comprende 88 perfiles correspondientes a Neferhotep $(\mathrm{n}=22)$, miembros de su familia $(n=11)$, Amenhotep $(n=1)$ e integrantes del cortejo fúnebre $(n=54)$, ya sean de la elite tebana como así también sirvientes. Los mismos fueron relevados mediante fotografías digitales tomadas in situ (Dra. M.V. Pereyra) y láminas publicadas (Davies, 1933, vol. I; Pereyra et al., 2006) que fueron escaneadas para su inclusión en el análisis.

Una vez seleccionados los perfiles de los individuos que integran el análisis y habiendo sido descartados aquellos que no presentan las condiciones necesarias para su estudio morfométrico (dada la escasa precisión que ofrecen por problemas de deterioro), se necesitó de una imagen digital con igual nivel de resolución (establecido en $100 \mathrm{dpi}$ ) por cada retrato. Las figuras utilizadas se encuentran de perfil, dados los modos típicos de representación en el Egipto antiguo, siendo todas orientadas o reorientadas en el mismo sentido -hacia la izquierda- y haciendo coincidir el mentón con una línea horizontal ubicada a modo de base. Estos procedimientos fueron implementados para estandarizar la posición y traslación de las figuras, lo cual constituye un requisito del método. En algunos casos, Neferhotep es representado con barba (ver Figura 5.3). Dicho rasgo no fue incluido en las comparaciones de los perfiles, en los casos en los que estaba presente, dado que los puntos morfométricos mediante los cuales se captura la forma deben ser homólogos entre las diferentes imágenes.

A propósito de los integrantes del cortejo, cabe destacar que no se cuenta con una identificación estricta de sus identidades, como tampoco es posible saber si se trata de personajes reales; no obstante su relevancia se sustenta en la pertenencia de tales individuos a grupos sociales, que se supone que se desempeñaban en distintas instancias de los ritos funerarios.

\section{Resultados}

La aplicación de técnicas morfométricas se orientó a resolver algunas conceptualizaciones previas en cuanto a las formas de producción iconográfica, y a reconocer la existencia de homogeneidad / variabilidad de diseños, que dependiendo del observador resultaban a la vez semejantes o disímiles, por no contar con medios de resolución independientes. A continuación se presentan los resultados de acuerdo con cada uno de los objetivos y comparaciones propuestas.

\subsection{Variaciones morfológicas entre retratos femeninos y masculinos}

Según los actores sociales representados en la TT49 fue posible reconocer 60 hombres y 28 mujeres.

En la Figura 3 se presenta un análisis de componentes principales (ACP) sobre las coordenadas de forma, donde se observa la distribución de los retratos según las variaciones morfológicas que presentan, diferenciándose el sexo según colores.

Los dos primeros componentes del ACP explican un 65.4\% de las variaciones morfológicas de la muestra. Las figuras localizadas en los márgenes de los ejes (CP1 y 2) representan los extremos de variación morfológica de cada componente (perfiles en color negro), en comparación con la forma promedio de la muestra bajo análisis (perfil en color gris). De esta manera es posible apreciar visualmente la magnitud de las variaciones con respecto a la forma media, la cual se localiza en la intersección de los ejes (coordenadas 0,00).

El CP 1, que da cuenta de un 41.2\% de las variaciones morfológicas, evidencia un continuo de variación que va desde retratos con frente alargada, nariz pequeña, labios sin diferenciación y mentón relativamente corto en los puntajes positivos (sector derecho del gráfico) a retratos de frente corta, nariz y labios prominentes y mentón relativamente alargado en los puntajes negativos (sector izquierdo del gráfico). El CP2, que 
explica un $24.2 \%$ de las variaciones, muestra retratos con frente corta, nariz redondeada, labios similares a la forma promedio y mentón sin mayores distinciones en los puntajes positivos (sector superior del gráfico) en oposición a retratos de frente alargada con nariz y labios remarcados y mentón alargado en los puntajes negativos (sector inferior del gráfico).

De acuerdo con su distribución en el espacio de forma, los retratos masculinos y femeninos no parecen mostrar una agrupación diferencial que sugiera una forma particular de representación según el sexo. Sin embargo, debemos tener en cuenta que el ACP no es una técnica diseñada con el fin de diferenciar grupos, sino que persigue el objetivo de describir variaciones entre individuos asumiendo que corresponden a la misma población (Manly, 1994; Strauss, 2010).

FIGURA 3.

Análisis de componentes principales de las coordenadas de forma diferenciando el sexo de los retratos (Puntos negros: retratos femeninos. Puntos grises: retratos masculinos).

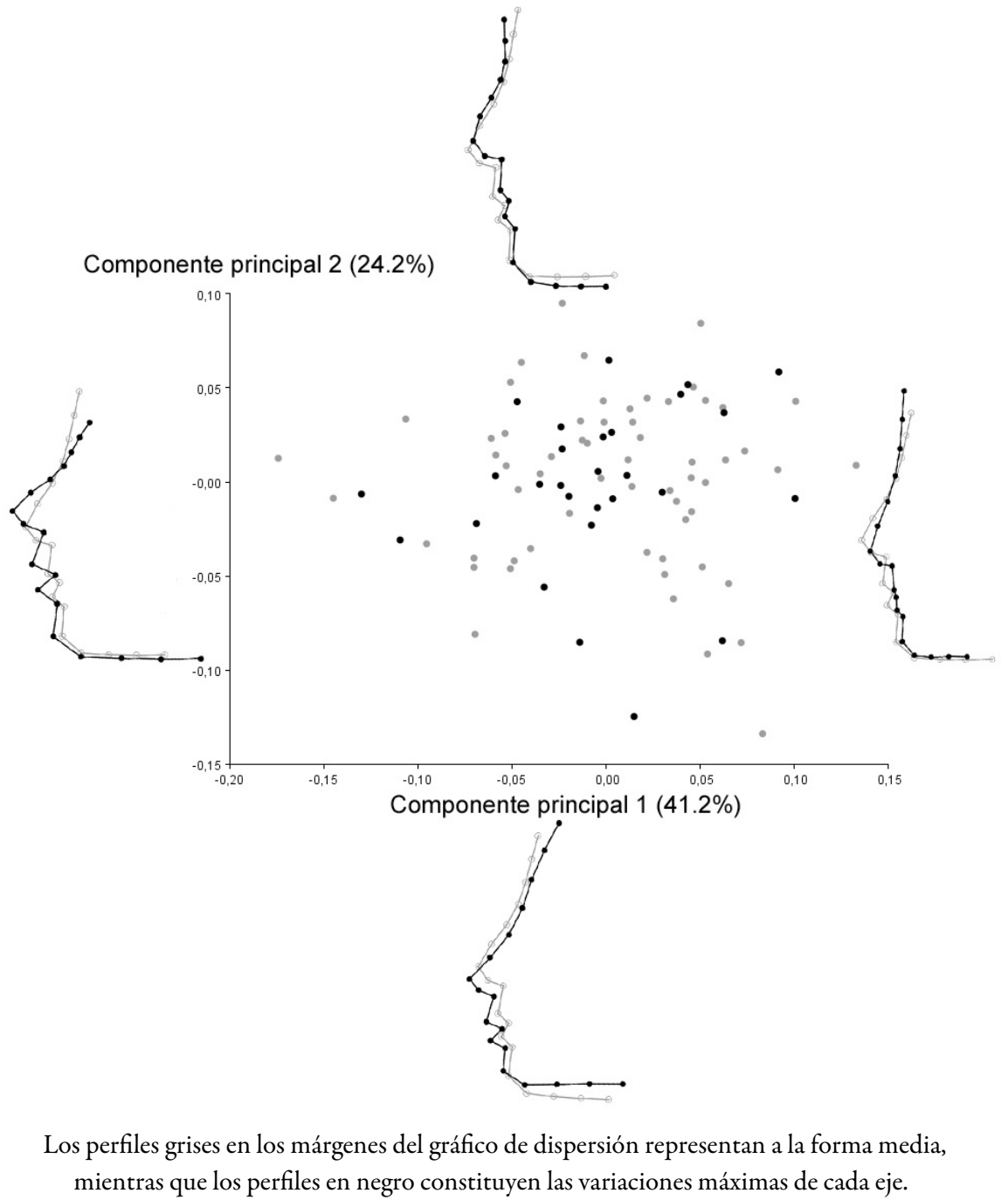

Con el objetivo de evaluar si los retratos femeninos y masculinos muestran variaciones morfológicas que permitan diferenciarlos, se llevó a cabo un análisis discriminante $(\mathrm{AD})$ utilizando la distancia de Mahalanobis para poner a prueba la hipótesis nula de igualdad en la forma media de los retratos según el sexo $(\alpha=0.05)$. La probabilidad fue calculada mediante permutación (10.000 corridas). El test arrojó diferencias significativas (D2: 2.32, p: 0.0077) entre la forma media de los retratos femeninos y masculinos, que puede observarse en la Figura 4. La tasa de clasificación correcta de las representaciones por sexo según la función discriminante es 
de $86.4 \%$ (Tabla 1). Por su parte, la validación cruzada mediante "leave-one-out" muestra que un 66\% de los casos serían clasificados correctamente si los mismos fueran considerados como "indeterminados", es decir, si nuevos casos "desconocidos" debieran ser clasificados (Tabla 2).

FIGURA 4.

Histograma de los puntajes discriminantes de los retratos según sexo (gris oscuro: retratos femeninos, gris claro: retratos masculinos) y forma media para cada grupo

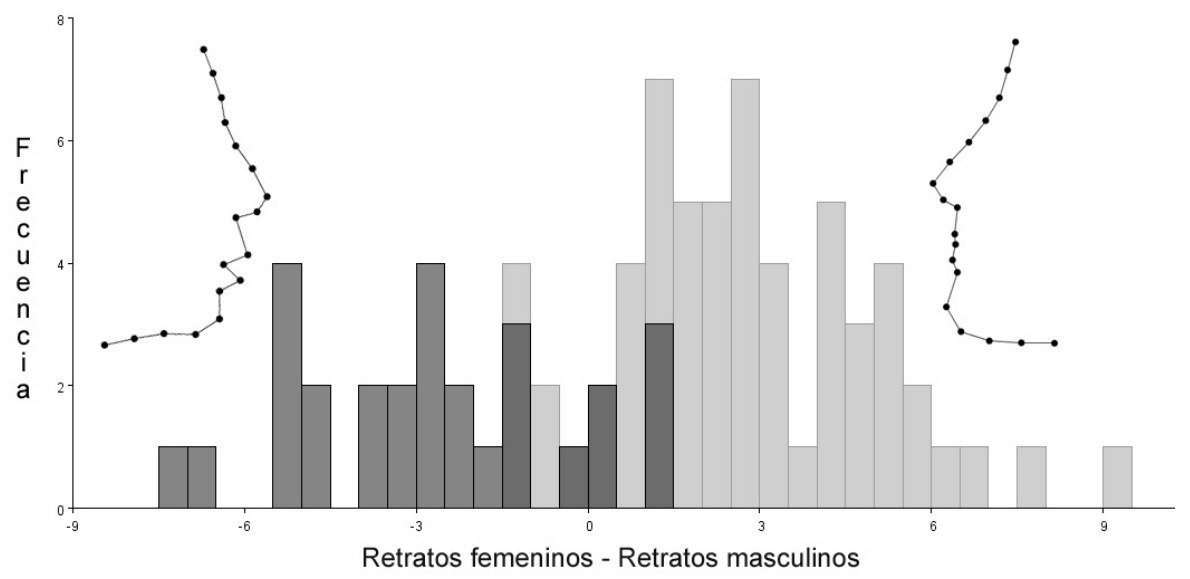

TABLA 1.

Casos asignados correcta e incorrectamente a su grupo de pertenencia (grupo a priori) mediante la función discriminante.

\begin{tabular}{|l|c|c|c|}
\hline Grupo & \multicolumn{2}{|c|}{ Grupo predicho } & \\
\hline a priori & Femenino & Masculino & Total \\
\hline Femenino & 23 & 5 & 28 \\
\hline Masculino & 7 & 53 & 60 \\
\hline
\end{tabular}

TABLA 2.

Casos asignados correcta e incorrectamente a su grupo de pertenencia (grupo a priori) mediante la validación cruzada

\begin{tabular}{|l|c|c|c|}
\hline Grupo & \multicolumn{2}{|c|}{ Grupo predicho } & \\
\hline a priori & Femenino & Masculino & Total \\
\hline Femenino & 17 & 11 & 28 \\
\hline Masculino & 19 & 41 & 60 \\
\hline
\end{tabular}

Si bien la diferencia en los porcentajes de error en la clasificación de los retratos según el sexo es pequeña (los retratos femeninos presentan un 6\% más de error en su clasificación que los masculinos) es interesante tener en cuenta para futuros análisis con un mayor tamaño de muestra si la presencia de un mayor porcentaje de asignación incorrecta sigue correspondiendo a los perfiles femeninos, lo cual puede sugerir algún aspecto 
ambiguo, en lo relativo a su forma de representación o bien a un forma andrógina de expresión visual, que engloba en alguna medida a ambos sexos.

\subsection{Variaciones en los retratos según categoría social (rango y desempeño)}

Las 88 figuras representadas en la TT49 fueron agrupadas conformando tres grupos de acuerdo con su estatus social, que en gran parte determina las actividades en las que se encuentran involucrados los individuos en la epigrafía de la tumba. El grupo 1 se encuentra conformado por los retratos de Neferhotep, que son los predominantes, y de su familia, entre los que se encuentra su esposa Merytra, sus padres y su bisabuelo (Figura 5). Dicho grupo suma un total de 33 retratos, siendo 22 los del dueño de la tumba.

FIGURA 5.

Algunas imágenes de Neferhotep y Merytra que formaron parte del grupo 1.

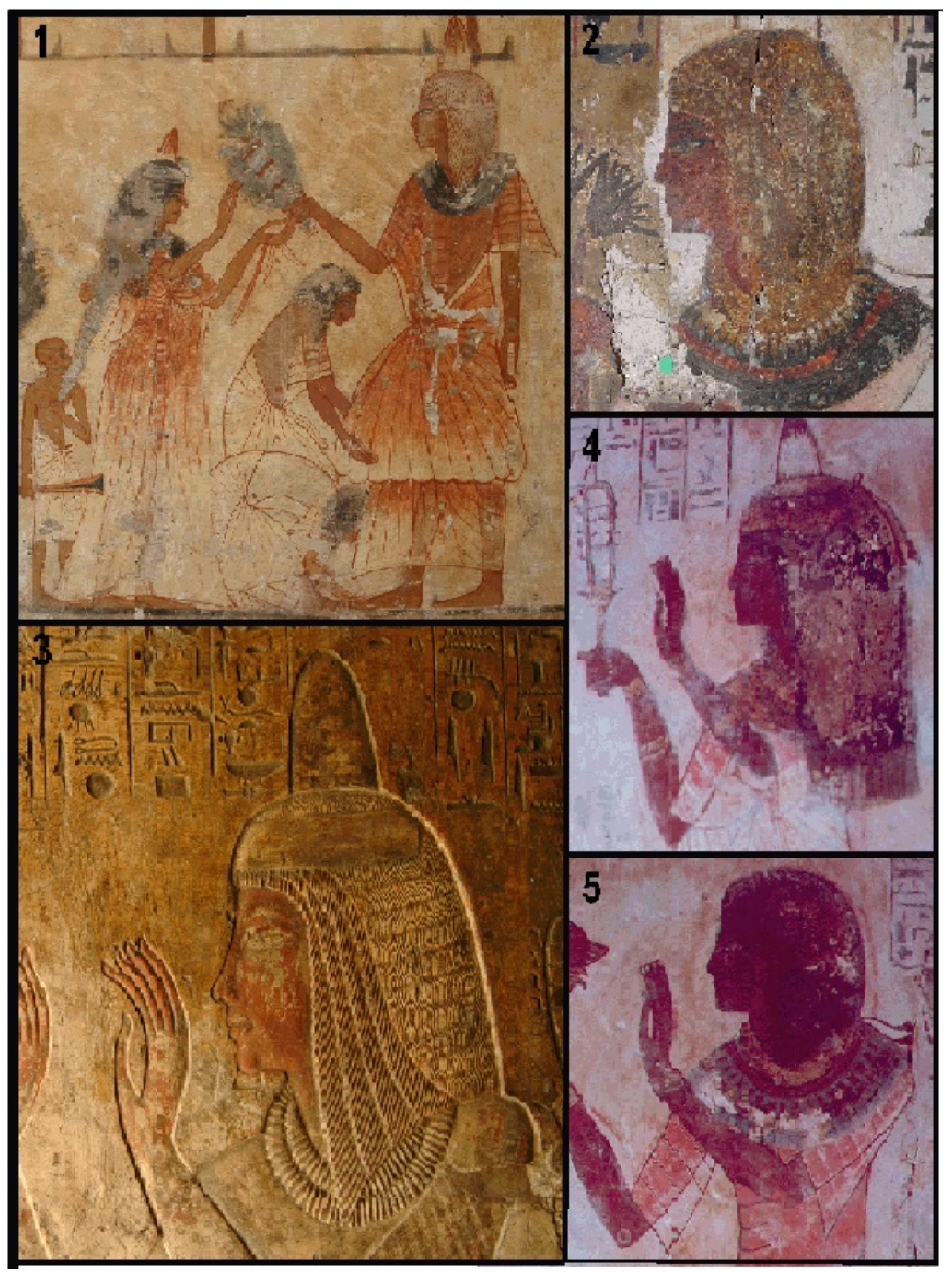

Referencias de las fotografías con respecto a las láminas de Davies (1933): 1) XLI, 2) LI, 3) XXXVI, 4 y 5) L.

Por otro lado, se ha conformado un segundo grupo que agrupa a diferentes personajes de la elite tebana, como ritualistas y sacerdotes, plañidera/os, borrachas y músicas que forman parte del cortejo. Así, el grupo 2 reúne a 22 individuos (Figura 6). 
FIGURA 6.

Algunas imágenes de plañidera/os que formaron parte del grupo 2.

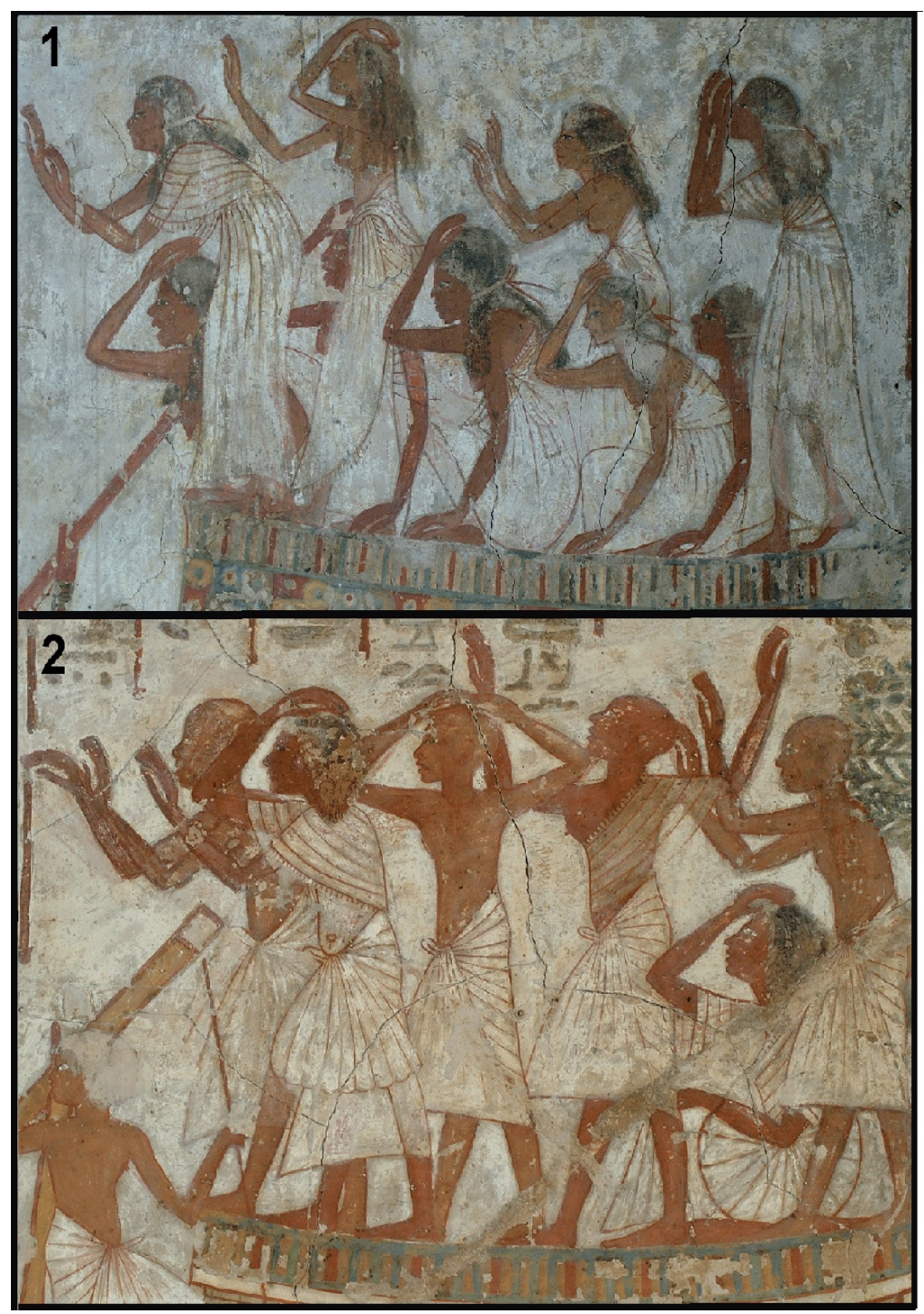

Referencias de las fotografías con respecto a las láminas de Davies (1933): 1) XXII, 2) XXIII

Finalmente, el grupo $3(n=33)$ se encuentra compuesto por los servidores, agrupando a figuras como los portadores de objetos y ofrendas, los remeros y las doncellas (Figura 7). Amenhotep fue la única de las 88 figuras registradas digitalmente no incluida en el análisis, ya que debido a su carácter divinizado consideramos que no era adecuado incluirlo en ninguno de los grupos diferenciados. 


\section{FIGURA 7.}

Algunas imágenes de doncellas (1) y remeros (2) que formaron parte del grupo 3.

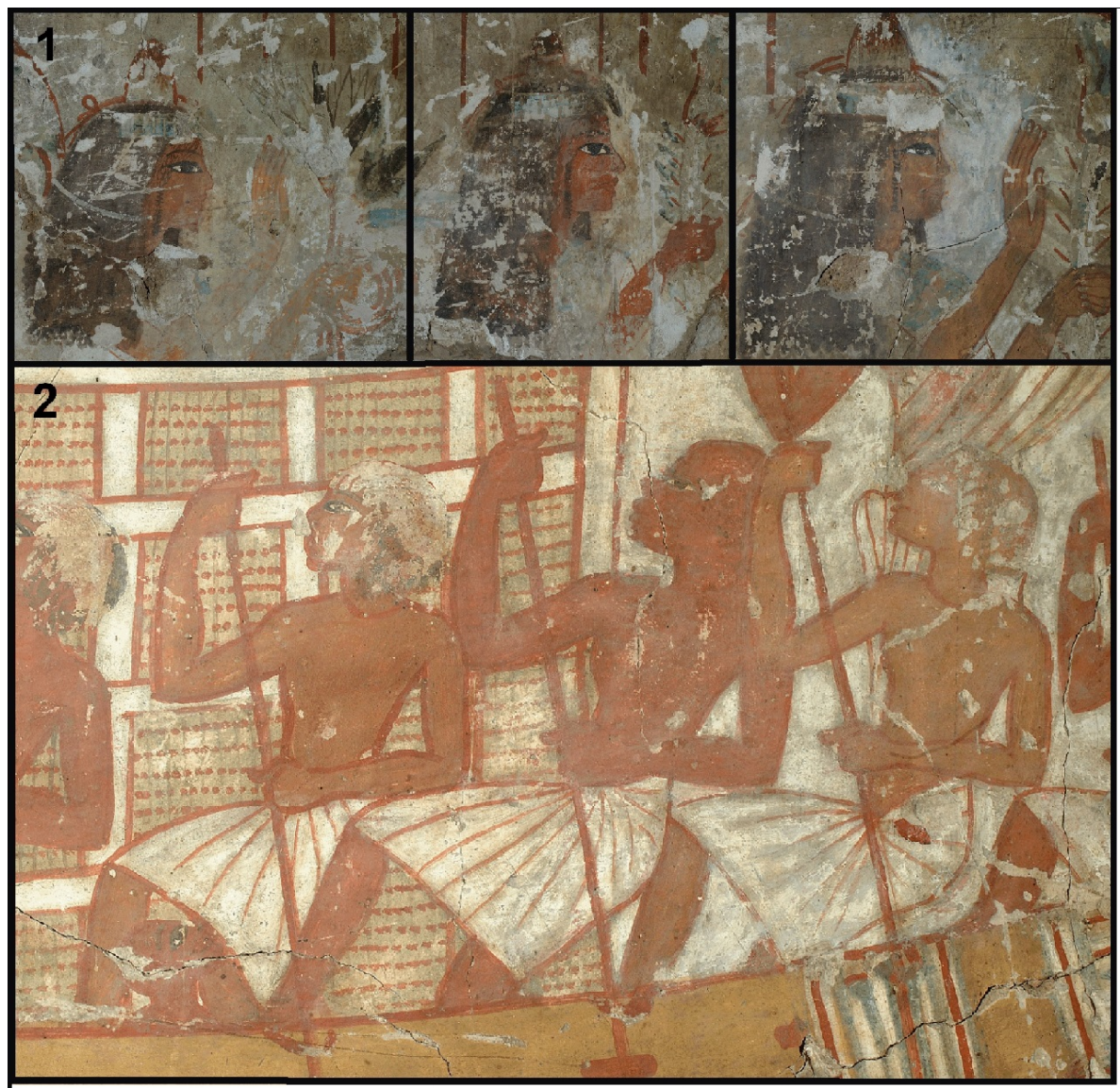

Referencias de las fotografías con respecto a dibujos publicados: 1) se corresponden con la figura 24 de Pereyra y otros (2006), 2) se corresponde con la lámina XXIII de Davies (1933).

Si en el análisis de componentes principales presentado anteriormente se diferencian en colores los tres grupos sociales en lugar del sexo, no es posible observar la conformación de "grupos naturales" (Figura 8). Sin embargo, al efectuar un análisis discriminante multigrupo (análisis de variantes canónicas, Webster y Sheets, 2010), el cual maximiza las diferencias entre los grupos definidos a priori, se obtienen diferencias significativas entre los tres grupos identificados (Tabla 3). Por consiguiente, es posible sostener que existen cánones representativos particulares que son distintivos del modo de representar los retratos de los diferentes personajes según su estatus (Figura 9). 


\section{FIGURA 8.}

Análisis de componentes principales de las coordenadas de forma según estatus social (puntos en gris claro: Neferhotep y su familia, cuadrados en gris oscuro: elite tebana, puntos negros: servidores).

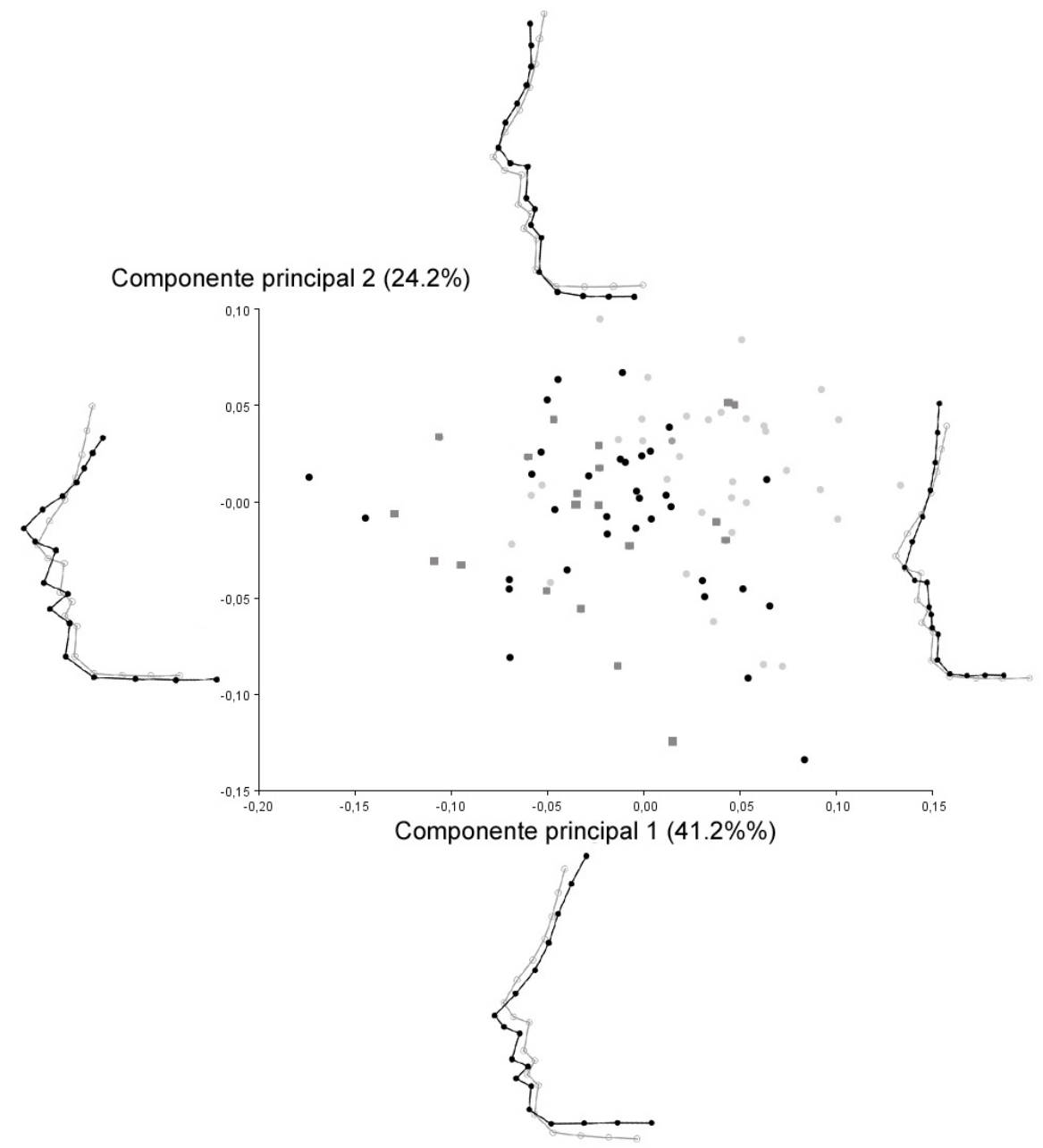

Los perfiles grises en los márgenes del gráfico de dispersión representan a la forma media, mientras que los perfiles en negro constituyen las variaciones máximas de cada eje.

TABLA 3.

Diferencias en la forma media según los grupos de retratos por estatus de los personajes de acuerdo con la distancia de Mahalanobis (valores de distancia entre paréntesis).

\begin{tabular}{|l|l|l|}
\hline Grupos & Elite & Neferhotep y familia \\
\hline Neferhotep y familia & $<.0001(4.12)$ & \\
\hline Servidores & $<.0001(3.11)$ & $<.0001(2.33)$ \\
\hline
\end{tabular}


FIGURA 9.

Análisis discriminante multigrupo (análisis de variantes canónicas) según estatus social (puntos en gris claro: Neferhotep y su familia, cuadrados en gris oscuro: elite tebana, puntos negros: servidores).

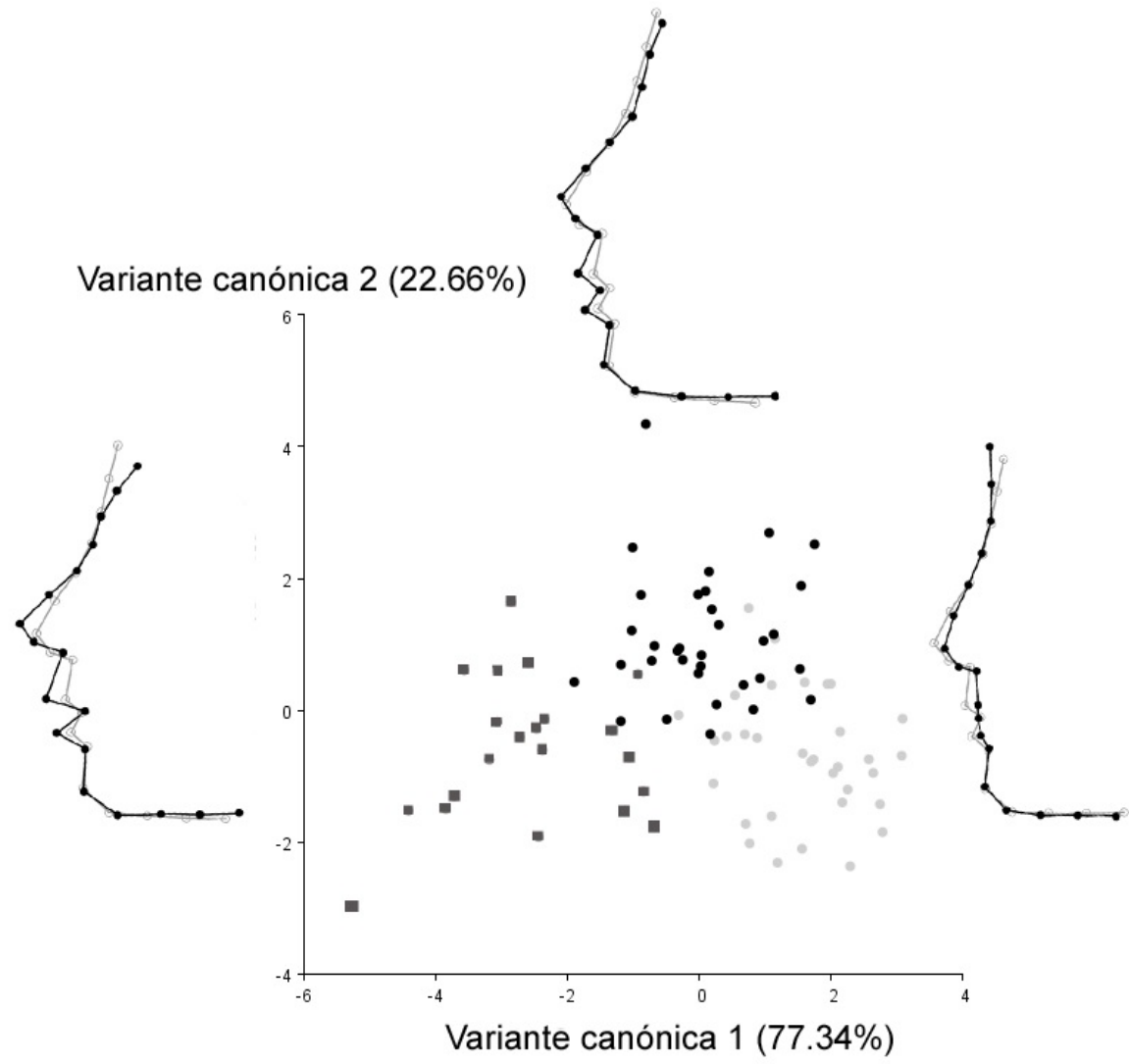

Los perfiles grises en los márgenes del gráfico de dispersión representan a la forma media, mientras que los perfiles en negro constituyen las variaciones máximas de cada eje, que se corresponden con los grupos diferenciados.

El eje 1 (VC1) del análisis disciminante multigrupo, que es el que explica las mayores variaciones entre los grupos, da cuenta de un $77.34 \%$ del total de la varianza. En los márgenes del gráfico de dispersión pueden observarse los rasgos morfológicos que caracterizan a cada uno de los grupos (perfiles en negro). Así, se observa que los retratos del grupo 1 (Neferhotep y familia) ocupan preferencialmente los puntajes positivos del eje 1 , y se caracterizan en general por rasgos poco marcados, en contraposición con el grupo 2 (elite), cuyos retratos muestran valores negativos en el eje 1 y rasgos prominentes, al igual que los personajes del grupo 3 (servidores), con puntajes positivos en el eje 2 (VC2). Las diferencias entre estos dos últimos grupos no parecen tan notorias a ojo desnudo como sí lo son con respectoal grupo 1. Sin embargo, estadísticamente los resultados son significativos en todos los casos (Tabla 3).

Si evaluamos los porcentajes de retratos clasificados erróneamente según la función discriminante (Tabla 4) y la validación cruzada (Tabla 5) podemos observar que el grupo de los servidores es el que presenta el porcentaje más elevado de clasificación incorrecta ( $45 \%$ en el primer caso y $61 \%$ en el segundo), lo cual posiblemente se encuentre en relación con una alta variabilidad interna al grupo que puede estar dada por la diversidad de personajes que agrupa. Dentro de este grupo, el $24 \%$ de los servidores son confundidos con miembros de la elite, tanto con la función discriminante como mediante la validación cruzada (Tablas 4 y 5 ). En el caso de la elite, el 19\% de los retratos son erróneamente clasificados como perteneciente al grupo de los servidores mediante la función discriminante, ascendiendo a $24 \%$ a través de la validación cruzada.

En general, la tasa total de clasificación correcta de los retratos según el estatus social de los personajes es inferior en ambos casos a la registrada en relación con la diferenciación por sexo $(59.77 \%$ por función 
discriminante y $43.68 \%$ por validación cruzada). Esto sugiere que los grupos definidos bajo este criterio deben ser revisados en análisis futuros con el objetivo de lograr una mayor homogeneidad interna que les otorgue mayor robustez. Si bien previamente se exploraron otras agrupaciones, considerando un mayor número de grupos y por consiguiente con mayor afinidad interna, el tamaño pequeño de la muestra es un limitante al respecto, al menos con la información digital con la que se cuenta actualmente.

TABLA 4.

Casos asignados correcta e incorrectamente a su grupo de pertenencia (grupo a priori) mediante la función discriminante.

\begin{tabular}{|l|c|c|c|c|}
\hline \multirow{2}{*}{ Grupo } & \multicolumn{3}{|c|}{ Grupo predicho } & \\
\hline a priori & Neferhotep y familia & Servidores & Elite & Total \\
\hline Neferhotep y familia & 22 & 6 & 5 & 33 \\
\hline Servidores & 7 & 18 & 8 & 33 \\
\hline Elite & 5 & 4 & 12 & 21 \\
\hline Total & 34 & 28 & 25 & 87 \\
\hline
\end{tabular}

TABLA 5.

Casos asignados correcta e incorrectamente a su grupo de pertenencia (grupo a priori) mediante la validación cruzada.

\begin{tabular}{|l|c|c|c|c|}
\hline \multirow{2}{*}{ Grupo } & \multicolumn{3}{|c|}{ Grupo predichos } & \\
\hline a priori & Neferhotep y familia & Servidores & Elite & Total \\
\hline Neferhotep y familia & 17 & 13 & 3 & 33 \\
\hline Servidores & 12 & 13 & 8 & 33 \\
\hline Elite & 5 & 8 & 8 & 21 \\
\hline Total & 34 & 34 & 19 & 87 \\
\hline
\end{tabular}




\section{Conclusiones}

Como señalamos al principio, la primera aplicación de las técnicas de MG al estudio de las representaciones parietales de la TT49, en particular al perfil de Neferhotep (Charlin y Manzi, 2017; Pereyra et al., 2016), no encontró diferencias significativas entre los retratos del dueño de la tumba efectuados en las distintas paredes, lo cual, en primera instancia, permitiría refutar la propuesta del desempeño de cuadrillas diferenciadas a cargo de la decoración de los lados norte y sur de la tumba. No obstante, antes de avalar o descartar explicaciones, pensamos que en alguna medida no estamos excentos de situaciones de equifinalidad en los procesos intervinientes. En este sentido, consideramos que la ausencia de variaciones notorias en las representaciones del dueño de la tumba responde a un programa decorativo altamente pautado, que minimizaría los márgenes de variación a causa de una fuerte supervisión y extrema especialización, a pesar de la probable existencia de cuadrillas.

Asimismo, por tratarse de retratos, se espera que la variación tolerada fuese escasa, al estar dirigida al reconocimiento de rasgos fisonómicos identificatorios y su elaboración formalizada en un número variable pero limitado de alternativas representativas.

Sin embargo, al valorar las representaciones según el sexo de los personajes o su rango social, se han registrado diferencias morfológicas significativas, es decir, poco probables de que ocurran sólo por azar. En el caso de comparación de los retratos entre personajes de diferente rango o desempeño, la tasa de clasificación correcta de los individuos según los grupos definidos a priori mostró que las mayores ambigüedades se registran entre los servidores y la elite tebana. El grupo correspondiente a los perfiles de Neferhotep y su familia es el que parece tener mayor homogeneidad interna, quizás en un intento por diferenciar al dueño de la tumba y sus parientes del resto de los personajes, destacando su rol protagónico como beneficiario de la tumba. Al mismo tiempo, es esperable que hubiesen artesanos especializados en ciertas clases de representaciones, como por ejemplo, retratistas encargados de representar al propietario de la tumba y a su familia, particularmente a aquellos ya fallecidos -padre, madre, abuelos-, a partir de rasgos de semejanzas con el pariente vivo, y otros encargados de retratar al resto de los personajes que forman parte de las escenas. Así, la representación de los perfiles de los tres grupos diferenciados parece seguir un programa altamente pautado a través de un diseño recurrente, pero que permite marcar diferencias entre los grupos sociales. Estas distinciones se manifiestan tanto en la forma de los perfiles, que a ojo desnudo parecen similares, como en gestos, acciones, vestimenta, adornos, equipamiento, y tamaño relativo de las figuras, entre otros, que no fueron incluidos en este análisis, debido al requisito de homología entre los rasgos comparados, y porque constituyen los atributos que muestran las mayores diferencias a la simple observación macroscópica, sin requerir de un análisis estadístico para su diferenciación.

Las implicancias en los modos de representación y la calibración de la variabilidad de los perfiles bajo estudio se dirigen hacia la detección de similitudes de diseño, a razón de la aplicación de modelos estandarizados y estrictamente supervisados, ya sea por exigencia y excelencia del artesano como por control externo. Dichos estándares se orientarían a lograr una mayor identidad entre rasgos que se posicionan como semejantes (miembros del cortejo fúnebre) o iguales (persona individualizada), o bien tienden a alcanzar "un parecido", justificado en el hecho de mostrar la presencia de alguien, como razón suficiente para sustentar su existencia y eficacia funcional en la práctica ritual.

La estandarización que se supone en las estrategias de representación para los beneficiarios del otorgamiento de tumbas genera la expectativa de que esta metodología, propuesta para el análisis de la TT49, cuenta con el potencial de ser extensible al análisis de otras tumbas de la necrópolis tebana.

Finalmente, consideramos que las láminas publicadas por Davies (1993), que comprenden calcos posteriormente digitalizados, podrían contener sesgos debido a la imprecisión de seguir trazos sobre las paredes, como así también las fotografías digitales utilizadas en este trabajo, a causa de los diversos ángulos y distancias de toma. Si bien nos proponemos en futuros trabajos controlar estas fuentes de variación, 
comparando los registros de diferentes copistas, la expectativa es que las variaciones producto de estos factores no sean tales como para que los actores sociales incluidos en los grupos diferenciados muestren cambios notorios que alteren los resultados aquí presentados.

\section{BibLiografía}

Ackermann, R. (2002). Patterns of covariation in the hominoid craniofacial skeleton: implications for paleoanthropological models. Journal of Human Evolution, 42, 167-187.

Assmann, J. (2004). The Ramesside Tomb and the Construction of Sacred Space. En N. Strudwick y J. Taylor (eds.), The Theban Necropolis. Past, Present and Future (pp. 46-52). London: British Museum.

Assmann, J. (2005). Death and Salvation. Ithaca: Cornell University Press.

Bastir, M., Rosas, A. y Sheets, H.D. (2005). The morphological integration of the hominoid skull: a partial least squares and PC analysis with implications for European Middle Pleistocene mandibular variation. En D. Slice (ed.), Modern morphometrics in physical anthropology (pp. 265-284). New York: Kluwer Academic/Plenum Publishers.

Bookstein, F. (1990), Introduction and overview: geometry and biology, in J. Rohlf and F. Booksteineds., Proceedings of the Michigan morphometrics workshop, Ann Arbor, The University of Michigan Museum of Zoology, pp. 61-74.

Bookstein, F. (1991). Morphometric tools for landmark data. Geometry and biology. New York: Cambridge University Press.

Bookstein, F. (1996). Combining the tools of geometric morphometrics. En L. Marcus, M. Corti, A. Loy, G. Naylor y D. Slice (eds.), Advances in Morphometrics (pp. 131-151). New York: Plenum Press.

Bookstein, F. (1996/7). Landmarks methods for form without landmarks: Morphometrics of group differences in outline shape. Medical Image analysis, 1(3), 225-243.

Buchanan, B., Collard, M., Hamilton, M. y O’Brien, M. (2011). Points and prey: a quantitative test of the hypothesis that prey sizes influences early Paleoindian projectile point form. Journal of Archaeological Science, 38, 852-864. doi: 10.1016/j.jas.2010.11.007

Buchanan, B., O’Brien, M. y Collard, M. (2014). Continent-wide or region-specific? A geometric morphometricsbased assessment of variation in Clovis point shape. Journal of Archaeological Science, 6, 145-162. doi: 10.1007/ s12520-013-0168-x

Cardillo, M. (2005). Some Applications of Geometric Morphometrics to Archaeology. En A. Elewa (ed.), Morphometrics for Nonmorphometricians (pp. 325-355). Verlag- Berlin- Heidelberg: Springer.

Carpiceci, A.C. (2009). Arte e historia: Egipto 500 años de civilización. Florencia: Casa Editrice Bonechi.

Charlin, J. y González-José, R. (2012), Size and shape variation in Late Holocene projectile points of southern Patagonia. A geometric morphometric study. American Antiquity, 77(2), 221-242.

Charlin, J. y Hernández Llosas, M.I. (2016). Morfometría geométrica y representaciones rupestres: explorando las aplicaciones de los métodos basados en landmarks. Arqueología, 22(1), 103-125.

Charlin, J., y Manzi, L. (2017). Estudio de las representaciones de Neferhotep en las paredes norte y sur de la TT49 a través de la morfometría geométrica. En A. Brancaglion Jr. y G. Chapot (Eds.), Estudos de Egiptologia IV (pp. 215-229). Recuperado en http://www.seshat.com.br/publicacoes/

Charlin, J., Cardillo, M., y Borrazzo, K. (2014). Spatial Patterns in Late Holocene Lithic Projectile Point Technology of Tierra del Fuego (Southern South America): Assessing Size and Shape Changes. World Archaeology, 46, 78100.

Choisy, A. (2007). El arte de construir en Egipto. Madrid: Editorial Inst. Juan de Herrera.

Davies, N. G. (1933). The Tomb of Neferhotep at Thebes. New York: Metropolitan Museum of Art of New York.

Fantechi, S., y Zingarelli, A. (2003). El bouquet de Amón y su simbología en TT49. IX Jornadas Interescuelas/ Departamentos de Historia, Universidad Nacional de Córdoba, Córdoba. 
González-José, R., Bortolini, M.C., Rodrigues Dos Santos, F. y Bonnato, S. (2008). The peopling of América: Craniofacial shape variation on a continental scale and its interpretation from an interdisciplinary view. American Journal of Physical Anthropology, 137, 175-187.

Hammer, Ø. (1999-2017). PAST PAleontological STatistics version 3.17. Reference manual. Recuperado del sitio web de la Universidad de Oslo, Museo de Historia Natural: http://folk.uio.no/ohammer/past/past3manual.pdf.

Hammer, Ø., Harper, D.A.T. y Ryan, P.D. (2001). PAST. Paleontological Statitics software package for education and data analysis. Paleontologia Electronica, 4(1), 9 pp.

Hermoso Cuesta, M. (2008). Breve historia del arte egipcio. Barcelona: Editorial Montesinos.

Kampp, F. (1996). Die Thebanische Nekropole zum wandel des Grabgedankens von der XVIII bis zur XX Dynastie. Mainz am Rhein: Philipp von Zabern.

Kendall, D. (1977). The diffusion of shape. Advances in Applied Probability, 9, 428-430

Kendall, D. (1989). A survey of the statistical theory of shape. Statistical Science, 4(2), 87-120.

Klingenberg, C. (2011). MORPHOJ: an integrated software package for geometric Morphometrics. Molecular Ecology Resources, 11,353-357.

Manly, B. (1994). Multivariate statistical methods: Aprimer. London: Chapman \& Hall/CRC.

Manzi, L. (2009-2010). Intervenciones y registro de daños en la tumba de Neferhotep, la colina de el-Khokha, Tebas occidental, Egipto. Avances Revista del Area Artes, 16, 187-201.

Manzi, L. (2012). La jerarquización del espacio a través de la distribución de tumbas privadas en Tebas Occidental, Egipto. Novos Trabalhos de Egiptologia Ibérica, 1, 637-655.

Manzi, L. (2016). Monumentalización y evocación en el paisaje de Tebas occidental, Egipto. Mundo Antigo, 9 , 191-205.

Marcus, L., Bello, E., y Garcia-Valdecasas,A. (Eds.) (1993). Contributions to Morphometrics. Madrid: Museo Nacional de Ciencias Naturales, Consejo Superior de Investigaciones Científicas.

Mitteroecker, P.y Bookstein, F. (2008). The evolutionary role of modularity and integration in the hominoid cranium. Evolution, 62(4), 943-958.

Mitteroecker, P. y Gunz, P. (2009). Advances in Geometric Morphometrics. Evolutionary Biology, 36, 235-247.

Parra Ortiz, J.M. (2011). El Antiguo Egipto. Madrid: Marcial Pons Ediciones de Historia.

Pereyra, M.V. (2011a). El libro para salir al día. Buenos Aires: Editorial Dunken

Pereyra, M.V. (2011b). El gran templo de Amón en la tumba de Neferhotep TT49. Revista del Instituto de Historia Antigua Oriental, 17, 17-26.

Pereyra, M.V. (2012). El palacio real en el umbral del Más Allá. Novos Trabalhos de Egiptologia Ibérica, 1, 871-883.

Pereyra, M.V., Alzogaray, N., Zingarelli, A., Fantechi, S., Vera, S., Verbeek, Ch., Brikmann, S., y Graue, B. (2006). Imágenes a preservar en la Tumba de Neferhotep (TT49). Tucumán: Universidad Nacional de Tucumán.

Pereyra, M.V., Charlin, J. y Manzi, L. (2016). Hetep di nesu y su lógica en el Egipto faraónico: la necrópolis tebana ca. 1550-1200 a.C. Trabajo presentado en XIX Congreso Nacional de Arqueología Argentina, San Miguel de Tucumán.

Porter, B., y Moss, R. (1985). Topographical Bibliography of Ancient Egyptian Hieroglyphic Texts, Reliefs, and Paintings. I. The Theban Necropolis, Part 1. Private Tombs. Oxford: Griffith Institute.

Rohlf, F.J. (1990). Rotational Fit (Procrustes) Methods. En F.J. Rohlf y F. Bookstein (eds.), Proceedings of the Michigan Morphometics Workshop (pp. 227-236). Ann Arbor: The University of Michigan Museum of Zoology.

Rohlf, F.J. (1993). Relative warps analysis and an example of its applications to mosquito wings. En L. Marcus, E. Bello y A. García-Valdecasas (eds.), Contributions to morphometrics (pp. 131-159). Madrid: Museo Nacional de Ciencias Naturales.

Rohlf, J. (2008). tps Utility version 1.40. Department of Ecology and Evolution, State University. New York: Stony Brook. 
Rohlf, J. (2013a). tpsDig2 version 2.17. Department of Ecology and Evolution, State University. New York: Stony Brook.

Rohlf, J. (2013b).tps Relative Warps. version 1.53. Department of Ecology and Evolution, State University. New York: Stony Brook.

Rohlf, J., y Bookstein, F. (Eds.) (1990). Proceedings of the Michigan morphometrics workshop. Ann Arbor: The University of Michigan Museum of zoology.

Rohlf, F.J. y Slice, D. (1990). Extensions of the Procrustes method for the optimal superimposition of landmarks. Systematic Zoology, 39(1), 40-59.

Slice, D. (Ed.) (2005). Modern morphometrics in Physical Anthropology. Chicago: Chicago University.

Strauss, R. (2010). Discriminating groups of organisms. En A. Elewa(ed.), Morphometrics for nonmorphometricians (pp. 73-91). Berlin: Springer. DOI 10.1007/978-3-540-95853-6

Thulman, D. (2012). Discriminating Paleoindian point types from Florida using landmark geometric morphometrics. Journal of Archaeological Science, 39, 1599-1607.

Webstern, M. y Sheets, H.D. (2010). A practical introduction to landmark-based geometric morphometrics. Quantitative Methods in Paleobiology, 16, 163-188. doi.org/10.1017/S1089332600001868

Zelditch, M.L., Swiderski, D.L., Sheets, H.D., y Fink, W.L. (2004). Geometric Morphometrics for Biologists: A primer. London: Elsevier Academic Press. 